Working Paper 9604

\title{
BANK DEPOSIT RATE CLUSTERING: THEORY AND EMPIRICAL EVIDENCE
}

by Charles Kahn, George Pennacchi, and Ben Sopranzetti

Charles Kahn is a professor of finance at the University of Illinois; George Pennacchi is an associate professor of finance at the University of Illinois and a research associate at the Federal Reserve Bank of Cleveland; and Ben

Sopranzetti is an assistant professor of finance at Seattle University. The authors are very grateful to Douglas

Evanoff, Allen Berger, Richard Rosen, and Arlene Sopranzetti for help with the empirical work of this paper. Useful comments were provided by seminar participants at Indiana University, Seattle University, the University of Illinois, and the 1996 Winter Econometric Society Meetings. Correspondence may be sent to George Pennacchi, Department of Finance, University of Illinois, 1407 West Gregory Drive, Urbana, Ill. 61801. Phone: (217) 244-0952. FAX: (217) 244-3102. Email: gpennacc@uiuc.edu.

Working papers of the Federal Reserve Bank of Cleveland are preliminary materials circulated to stimulate discussion and critical comment. The views contained herein are those of the authors and not necessarily those of the Federal Reserve Bank of Cleveland or of the Board of Governors of the Federal Reserve System.

Working papers are now available electronically through the Cleveland Fed's home page on the World Wide Web: http://www.clev.frb.org.

July 1996

\begin{abstract}
The market prices of stocks and other assets tend to cluster on round fractions. A similar clustering is found in the interest rates paid on retail bank deposits. However, the theoretical rationales given for asset-price clustering are incompatible with the clustering of retail deposit rates. This paper proposes a theory based on depositors' limited recall. It shows that when banks exploit this phenomenon, deposit rates will tend to be set at round fractions and will be relatively "sticky" at these levels. The implications of this theoretical model are tested using money market deposit account and retail certificate of deposit interest-rate data from a sample of more than 500 banks.
\end{abstract}




\section{Introduction}

A central issue in economic theory is the determination of market prices, but standard price theory cannot explain several common pricing conventions. These conventions are difficult to rationalize because they depend on the pricing system's unit of account. For example, in many financial markets, asset prices tend to cluster around "even" fractions of currency units. Several papers, including Osborne (1962), Nierderhoffer (1965), Harris (1991), and Christie and Schultz (1994), document that integer-dollar stock prices are more common than half-dollar stock prices, which are more common than quarter-dollar prices, which are more common than eighth-dollar prices. This phenomenon occurs for both stock quotes and transaction prices, and is persistent through time and across different stocks and stock markets. Ball, Torous, and Tschoegl (1985) find a similar clustering in the London gold market's fixing (auction) prices, as do Goodhart and Curcio (1990) in foreign exchange rates. Colwell, Rushing, and Young (1994) show that residential real estate prices tend to cluster on whole thousands and five-hundreds.

Explicit rules can require that prices cluster at particular fractions, an example being stock-exchange regulations that allow price quotes at "tick" sizes no smaller than an eighth of a dollar. More interesting are cases where clustering is not mandated, but results from an implicit agreement (custom) among traders. Two main theoretical explanations for such agreements have been proposed in the literature. First, as discussed by Harris (1991) and Ball, Torous, and Tschoegl (1985), and as modeled by Brown, Laux, and Schachter (1991), the custom of clustering on discrete price sets can be a mechanism for reducing the cost of negotiating transactions. By limiting bids and offers to a given set of prices, negotiations can be consummated more rapidly, since frivolous revisions of quotes at minute increments cannot be made. Limiting quotes to rounded prices can also make recording prices easier, thereby decreasing errors from traders believing that they have traded at different prices. This implicit agreement can be self-enforcing if 
professional traders deal with each other on a repeated basis, since noncooperation by an individual could lead to his exclusion from future trading. ${ }^{1}$ As an alternative to this negotiationcost hypothesis, Christie and Schultz (1994) and Christie, Harris, and Schultz (1994) propose a second rationale for price clustering. In their view, an agreement to limit price quotes to round fractions may be motivated by the desire to maintain noncompetitive bid-ask spreads. They present evidence that dealers in NASDAQ stocks avoided odd-eighths price quotes in order to maintain quarter-point bid-ask spreads.

If clustering around even fractions is a device for reducing negotiation costs or maintaining noncompetitive bid-ask spreads, one would expect that even-fraction clustering would not be pervasive in markets where prices are not negotiated and traders do not make a two-way market (quote both bid and ask prices). Indeed, this appears to be the case in many retail markets where sales to consumers are typically not negotiated and almost always occur at the sellers' quotes. In these non-negotiated, one-way retail markets, the tendency is to quote "odd" prices, where an odd price (e.g., \$3.99) is defined as one whose right-most digits are just below a whole or “even" price (e.g., \$4.00). The unusually high occurrence of odd prices in retail markets, such as department, discount, and grocery stores, is well documented. For example, in an analysis of scanner data, Wisniewski and Blattberg (1983) found that over 80 percent of prices quoted by a major supermarket chain ended with the digit 9. Friedman (1967) and Kashyap (1995) also document this odd-pricing phenomenon.

The absence of negotiations and bid-ask spreads might explain why retail prices are generally not rounded, but the unusually high frequency of odd-pricing in these markets requires its own explanation. The convention of odd-pricing in non-negotiated retail markets might be

\footnotetext{
${ }^{1}$ Casual observation is consistent with repeated dealings being an important factor in supporting these implicit agreements. In situations where successive dealings are unlikely, as in the auctioning of unique goods, explicit rules that restrict prices are often enforced. For example, English auctions typically require that new bids exceed a standing bid by a minimum price increment.
} 
linked to the different incentives and lack of information possessed by retail consumers compared to wholesale market traders. Transactions in wholesale markets are typically large, so that minute percentage price differences can have major consequences. Negotiating to obtain the best possible price is a paramount concern for professional traders. In contrast, retail consumers, whose transactions are smaller, may have less incentive to analyze which seller is offering the best price. Unlike wholesale traders, who typically have instant access to price quotes from many other traders, retail consumers usually obtain quotes from sellers of a given product at different points in time. They receive price information, either through advertisements or when shopping, in a sequential manner, but it may not be worth their time and effort to carefully record different sellers' prices. Hence, retail consumers' ability to recall prior price quotes will affect their current buying decisions.

Importantly, experimental tests performed by Schindler and Wiman (1989) find that individuals tend to recall odd-ending prices less accurately than even-ending prices, and that expressing a price as odd-ending increases the likelihood that it will be underestimated when recalled. A biological explanation for this downward bias in recalling odd-ending prices is offered by Brenner and Brenner (1982). They propose a theory of fixed storage capacity which assumes that the extra decision of rounding the initially observed number is costly, so that the cheapest “transfer mechanism" involves simply storing the first digit. Hence, if a price's right-most digits are not stored in memory, odd-ending prices will tend to be underestimated. If firms recognize consumers' downward bias in recalling odd-ending prices, they may significantly increase the demand for their products by making odd-ending price quotes rather than slightly higher evenending ones. Even-ending quotes will then represent "pricing points" where product demand experiences a discrete decline. Blinder (1991) reports some empirical support for this notion. 
Based on interviews with firm managers, he finds that a majority were reluctant to cross the "psychological barrier" of raising prices from an odd-ending quote to an even-ending one.

Not all firms that market retail products or services quote prices, however. For example, financial institutions customarily quote interest rates (yields), rather than prices, for many of their fixed-income investments. An intriguing question is whether the retail customers of these financial firms suffer from a similar downward bias when recalling odd-ending yields and, if so, whether these firms attempt to exploit this behavioral phenomenon. Financial institutions would take advantage of this customer behavior by quoting retail loan rates with odd-ending yields (so that they would be underestimated when recalled), but, in contrast, by quoting retail deposit rates with even-ending yields (so that they would not be underestimated when recalled). There is some anecdotal evidence that banks may in fact engage in this practice. During 1986-87, Davis, Korobow, and Wenninger (1987) conducted a series of interviews with senior commercial and savings bank officers in the New York City area. In their article (page 8), they report:

One banker offered the explanation that as market rates have declined, banks have been reluctant to breach successive single digit "floors" (such as an even 6.00 percent) and have been particularly slow to cut MMDA (Money Market Deposit Account) rates below the old ceiling rate on regular savings deposits even though such cuts might be justified on cost of money grounds. Such a line of argument would suggest that the bankers believe that at least at some critical points, the rate elasticity of demand for MMDAs may be fairly high, so that they fear losing market share by cutting rates at such points.

While there is an extensive literature analyzing how banks set their retail deposit rates, the possibility that they might exploit the limited recall of their depositors has not been investigated. ${ }^{2}$ The goal of this paper is to consider such a possibility. We analyze a banking firm's optimal deposit-rate-setting behavior when some consumers have limited recall but others have full recall. In section II, we present a model in which the demand for bank deposits by

\footnotetext{
${ }^{2}$ Some recent research on banks' deposit-rate-setting behavior includes Diebold and Sharpe (1990), Hannan and Berger (1991), Neumark and Sharpe (1992), and Rosen (1995).
} 
full-recall consumers depends on the bank's actual interest rate (e.g., 3.29 percent), whereas the demand by limited-recall consumers depends on the integer floor of the actual rate (e.g., 3.00 percent). In this environment, we solve for a bank's profit-maximizing deposit rate as a function of its opportunity cost of funds (wholesale-market funding rate) and the proportion of limitedrecall consumers in its market.

We find that the bank's optimal deposit rate is set either at a whole integer or at an interior point that satisfies a particular first-order condition. The likelihood of rates being set to an integer increases along with the proportion of limited-recall consumers and the wholesale cost of funds. As a consequence, our theory predicts that retail deposit rates will tend to cluster on integer digits, but for an entirely different reason than those given for price clustering in negotiated, two-way financial markets. We also show that for a given cost-of-funds shock, the bank's deposit rate is less likely to change when it is currently at an integer value than when it is not. Thus, deposit rates tend to be "sticky" at integer values. In addition, although deposit rates become stickier as the bank's cost of funds increases, when changes do occur, they will tend to move the deposit rate from one integer to another.

One of the attractive features of studying the pricing behavior of a banking firm, as opposed to a nonfinancial firm, is that a relatively accurate measure of changes in "input" or "production" costs is available. Changes in a wholesale funding rate, such as the London Interbank Offer Rate (LIBOR), give a fairly precise measure of changes in a bank's input or opportunity costs. This allows for relatively powerful empirical tests of our model's predictions. In section III, we test the model's implications using monthly money market deposit account (MMDA) and retail certificate of deposit (CD) rates for more than 500 banks over a 10-1/2-year period. Our empirical tests strongly support the clustering and sticky-integer implications of the model. 


\section{A Model of Deposit Pricing with Limited-Recall Investors}

Consider the following demand relationship for a particular bank's retail deposits. Let $D(t)$ denote investors' date $t$ desired holdings of a given type of retail deposit:

$$
D(t)=D\left(r(t), r_{d}(t), x(t)\right),
$$

where $r_{d}(t)$ is the date $t$ percentage interest rate that the bank offers on this deposit, $r(t)$ is the date $t$ market rate on wholesale funds of the same maturity as the retail deposit, and $x(t)$ is a vector of other variables affecting deposit demand. Deposit demand is monotonically increasing in $r_{d}$.

The relationship in (1) is assumed to be the demand for deposit balances from full-recall investors, hereafter referred to as "sophisticated" investors. For limited-recall investors, hereafter referred to as "naive" investors, the functional form is the same, but instead of the argument $r_{d}$, naive investors base their demands on a noisy, downward-biased measure of the actual deposit rate. In the spirit of Schindler and Wiman (1989) and Brenner and Brenner (1982), we assume that naive investors' demands depend on a truncated version of $r_{d}$, so that the interest rate they observe is the true deposit rate reported only as an integer-valued percentage rate. In other words, if the true offered depository rate is 5.30 percent, naive investors will observe 5.00 percent.

We will denote by $[r]_{-}$the truncation, or integer floor, of the real variable $r$. Similarly, let $[r]_{+}$denote the integer ceiling of the variable $r$. Thus, the demand curve for naive investors can be represented by

$$
D\left(r(t),\left[r_{d}(t)\right]_{-}, x(t)\right) \text {. }
$$

Let $\kappa$ be the proportion of potential bank customers who are naive, so that $1-\kappa$ is the proportion who are sophisticated. Also, let $c$ be the bank's non-interest expense per dollar of deposit. Then, the following function represents the bank's profits at date $t$ from issuing retail deposits: 


$$
\left(r-r_{d}-c\right)\left[(1-\kappa) D\left(r, r_{d}, x\right)+\kappa D\left(r,\left[r_{d}\right]_{-}, x\right)\right]
$$

We can now characterize the bank's optimal choice of its deposit rate when it faces both sophisticated and naive investors. We assume that $\left(r-r_{d}-c\right) D\left(r, r_{d}, x\right)$ is a concave function of $r_{d}$, so that in the absence of naive investors, the solution to the bank's optimization problem could be characterized by its first-order conditions. Let $r_{d}^{s}$ be the value that maximizes $\left(r-r_{d}-c\right) D\left(r, r_{d}, x\right)$. In other words, $r_{d}^{s}$ is the optimal deposit rate if the bank faces only sophisticated investors. The following theorem demonstrates that this rate is approximately the optimum in the presence of naive investors.

\section{Theorem 1. When some investors are naive, the bank's optimal deposit rate is in the range} $\left[\left[r_{d}^{s}\right]_{-},\left[r_{d}^{s}\right]_{+}\right]$

Proof: First, consider the case in which the bank is restricted to setting integer-valued (truncated) deposit rates. In this case, its profits from naive and sophisticated depositors will be equal, since deposit demand for the two groups will be the same. Furthermore, because $\left(r-r_{d}-c\right) D\left(r, r_{d}, x\right)$ is assumed to be concave in $r_{d}$, profits are also concave when interest rates are restricted to integer values, so that they will be highest at either $\left[r_{d}^{s}\right]_{-}$or $\left[r_{d}^{s}\right]_{+}$.

Now consider the general case in which the bank can set a non-integer-valued deposit rate. We can show that as long as $r_{d}$ is less than $\left[r_{d}^{s}\right]_{-}$, profits will increase by increasing the interest rate to $\left[r_{d}^{s}\right]_{-}$; correspondingly, it can also be shown that if interest rates are above $\left[r_{d}^{s}\right]_{+}$, then profits will increase by decreasing the interest rate to $\left[r_{d}^{s}\right]_{+}$. To demonstrate the first of these claims, note that concavity ensures that since $\left[r_{d}^{s}\right]_{-}$is less than $r_{d}^{s}$, profits from the sophisticated investors increase by bringing the interest rate up to $\left[r_{d}^{s}\right]_{-}$. The result for the naive investors is almost as straightforward. By going through two steps, profits from them can be shown to rise as 
well. From any initial interest rate $r_{d}$, bring interest rates down to $\left[r_{d}\right]_{-}$. This increases profits from naive investors. Next, increase profits further by moving from $\left[r_{d}\right]_{-}$to $\left[r_{d}^{s}\right]_{-}$. QED

The effect of including naive investors is illustrated in figure 1, which shows a bank's profit as a function of its deposit rate for various proportions of naive investors in the population. ${ }^{3}$ When all investors are sophisticated $(\kappa=0)$, as indicated by the solid line, profits are a smooth function of the offered interest rates, and the profit-maximizing rate is $r_{d}^{s}=6.5$ percent. In contrast, when three-quarters of the investors are naive $(\kappa=.75)$, as indicated by the long dashed line, bank profits increase dramatically as the interest rate moves from, say, 5.9 percent to 6.0 percent, as this brings in a large number of depositors. From that point, small increases in interest rates decrease profits, until the next breakpoint is achieved. Thus, the profitable thing to do when most investors are naive is to set the deposit rate at a breakpoint.

When many, but not all, investors are sophisticated, it may be optimal to choose an interior deposit rate, although this rate will not be the same as the optimal rate that would be set when all investors are sophisticated. Figure 1 gives an example of this for the case in which naive investors make up one-quarter $(\kappa=.25)$ of all depositors. As indicated by the short dashed line, the profit-maximizing interest rate is at the interior rate of 6.34375 percent.

Theorem 2. When some investors are naive, the bank's profit-maximizing deposit rate is either one of the endpoints of the interval described in Theorem 1, or a point in the interior of this interval that satisfies the following first-order condition:

\footnotetext{
${ }^{3}$ The profit function in figure 1 assumes that $c=.005$ and $D=a_{0}+a_{1} r+a_{2} r_{d}$, where $a_{0}=0, a_{1}=-6,000$, and $a_{2}=10,000$. This implies that in the absence of naive investors, the profit-maximizing deposit rate is $r_{d}^{s}=$ $.5\left[\left(1-a_{1} / a_{2}\right) r-c-a_{0} / a_{2}\right]=.8 r-.0025$. Assuming a market interest rate of $r=8.4375$ percent gives $r_{d}^{s}=6.5$ percent. These parametric assumptions are close to the parameter estimates for MMDAs found in Hutchison and Pennacchi (1996).
} 


$$
r-r_{d}^{*}-c=\frac{(1-\kappa) D\left(r_{d}^{*}\right)+\kappa D\left(\left[r_{d}^{*}\right]_{-}\right)}{(1-\kappa) \frac{\partial D\left(r_{d}^{*}\right)}{\partial r_{d}^{*}}}
$$

Roughly speaking, this first-order condition says the following: The optimal deposit rate is determined by balancing the benefits of increasing the interest rate spread with the cost of losing deposit market share. The more naive depositors there are, the lower the cost to market share of a small decrease in the deposit rate. Thus, as long as the choice is interior to the interval, the deposit rate decreases with increases in the proportion of naive individuals. Eventually, of course, the number of naive investors becomes great enough that the optimum is a breakpoint -- the solution jumps to that breakpoint (whole-digit interest rate) and remains there for further increases in the proportion of naive individuals. The jump may be up or down. In figure 1, we have chosen a borderline example, so that profits are the same for a jump in either direction.

This theorem gives us a direct means for calculating the optimum. We begin by taking the optimum in the absence of naive individuals and use it to find the boundary points. We then compare profits at those points with profits at the value where the first-order condition is satisfied. Figure 2 plots the optimal deposit rate as a function of the bank's wholesale market rate, $r$, for a given proportion ( $\kappa=50$ percent) of naive individuals in the population. ${ }^{4}$ Notice that when the wholesale market rate is low, the optimal deposit rate will be a relatively smooth function of the market rate. However, as the market rate increases, the function becomes discontinuous, jumping from one breakpoint to another. Intuitively, when the market rate is fairly low, the incremental profit from sophisticated depositors' increased demand is large enough to outweigh the marginal cost of raising the quoted deposit rate. Of course, the opposite is true when the market rate is relatively high.

\footnotetext{
${ }^{4}$ Figure 2 makes the same demand and non-interest cost assumptions made in figure 1 . See footnote 3.
} 
Figure 2 illustrates that as the wholesale market rate increases, the likelihood of the bank setting its retail deposit rate at a breakpoint should also rise. In addition, once the quoted interest rate is at a breakpoint, the likelihood of the bank changing its deposit rate decreases for any given change in the market rate. In other words, deposit rates are stickier when they are currently at an integer value. Figure 2 also demonstrates that although the bank's propensity to change its deposit rate decreases with an increase in market rates, when it does make a change, the change will, ceteris paribus, tend to be greater in magnitude.

\section{Empirical Evidence}

\section{III.A Data Description and Preliminary Analysis}

To test the implications of the model presented in the previous section, we obtained data on bank deposit rates from the Federal Reserve System's Survey of Selected Deposits and Other Accounts. This data set contains monthly retail deposit rates paid by over 500 banks during the week ending on the last Wednesday of each month. Our sample period extends from November 1983 to May 1994 and contains 42,202 observations of rates paid on MMDAs, 49,137 observations on three-month CDs (CD3s), 50,340 observations on six-month CDs (CD6s), and 49,909 observations on 12-month CDs (CD12s). Although the CD rates in this survey are for small-denomination $(<\$ 100,000)$ retail CDs, investors' balances held in CDs are generally larger than those in MMDAs. Also, the potential investor market for CDs is often greater than for MMDAs. The relevant market for MMDAs is generally limited to the bank's local depositor market, whereas CDs may be marketed to investors nationwide through CD brokers. ${ }^{5}$ An implication of these differences is that the proportion of naive investors should be relatively

\footnotetext{
${ }^{5}$ Berger and Hannan (1989) find significantly lower rates paid on MMDAs, CD3s, and CD6s by banks in more concentrated local markets, although the link was strongest for MMDAs. No such relationship was found for CD12s.
} 
greater for MMDAs than for CDs. Thus, one would expect the effects of limited recall by naive investors to be more clearly displayed in MMDAs than in CDs.

Our theoretical model implies that deposit rates set at or slightly above whole digits should be more common than rates set just below whole digits. In figures 3 to 6 , we present the frequency distributions of our sample of observations. These histograms show the percentage of observations at each basis point from 0 to 99 , where, for example, 0 refers to a whole-integer percentage deposit rate and 50 refers to a deposit rate set at half a percent. The figures for both MMDAs and CDs show that the single most common rate is one set at a whole digit: 15.8 percent of MMDA, 13.4 percent of CD3, 11.6 percent of CD6, and 14.2 percent of CD12 observations. In addition, there are "spikes" in the frequency distribution at the half-, quarter-, and three-quarterdigit levels, and, to a lesser extent, at every five basis points. For example, 48.5 percent of MMDA, 45.8 percent of CD3, 40.7 percent of CD6, and 41.9 percent of CD12 observations are rates set at either the whole, half, quarter, or three-quarter digit.

The inordinate frequency of deposit rates at multiples of quarter digits suggests that an extension of our basic model of depositor recall could consider secondary pricing points at half, quarter, and three-quarter digits in addition to the primary pricing point of the whole digit. The data appear consistent with banks' exploiting naive investors' limited recall, where recall is greatest at the whole digit, followed by recall at the half, quarter, and three-quarter digits. To capture this phenomenon, our model could be extended to allow for three categories of depositors: sophisticated full-recall depositors; naive depositors whose recall is limited to the quarter digit; and naive depositors whose recall is limited to the integer digit.

The existence of secondary pricing points at quarter digits might seem at odds with the notion that recall is inversely related to the number of decimal places held in memory. For example, why should 6.5 percent be easier to recall than 6.4 percent? Moreover, it would seem to 
be a contradiction to think that 6.25 percent or 6.75 percent could be remembered more accurately and with less downward bias than 6.3 percent or 6.7 percent, as the latter rates require fewer decimal places to be stored than the former. A resolution of this incongruity is that recall may not be a simple function of decimal places. Investors may have greater recall of 6.25 percent relative to 6.2 percent because the former is "stored" as 6 and a "quarter," not as 6 and .25 . While we know of no direct empirical evidence for this, it is not unreasonable that investors' recollection of "half," "quarter," or "three-quarter" could be more precise than a decimal place such as .1, .2, .3, $.4, .6, .7, .8$, or .9 . The memory "storage capacity" needed for the former (half, quarter, and threequarter being a three-element set) is less than that of the latter (the relevant decimals being an eight-element set).

Despite these secondary pricing points, the data support our basic model's implication that banks tend to set rates at, or slightly above, whole digits, and avoid rates slightly below whole digits. In table 1, we give the proportion of observations falling within quarter-integer "buckets," where the first, second, third, and fourth quartiles represent deposit rates ending in 0 to 24,25 to 49, 50 to 74, and 75 to 99 basis points, respectively. For all deposit types, the largest proportion of rate observations is always within the first quartile of basis points and the smallest proportion is always within the fourth quartile. As expected, these effects appear strongest for MMDAs. The hypothesis that the quoted deposit rates are uniformly distributed across basis-point quartiles is rejected at greater than the 1 percent level for every deposit type.

\section{III.B Evidence of the Relative Stickiness of Whole-Digit Deposit Rates}

As predicted by Theorem 2 and as illustrated in figure 2, a bank's propensity to change its deposit rate should be less sensitive to a given shock in its wholesale market funding rate when the deposit rate is currently at an integer value. In this section, we investigate whether the data support this notion of relative stickiness at whole-integer values. In testing this hypothesis, we 
proxy the wholesale market rate by the LIBOR having the same maturity as the retail deposit. ${ }^{6}$ In addition, we attempt to control for other sources of deposit rate stickiness that have been identified in previous research. For a given change in market rates, Hannan and Berger (1991) find evidence of greater MMDA rate stickiness for banks in more concentrated deposit markets. Thus, in testing the propensity to change deposit rates, we include a measure of local deposit market concentration -- the Herfindahl index of the local metropolitan statistical area. ${ }^{7}$ We also control for the extent of disequilibrium between market and deposit rates by including a variable that measures the spread between wholesale market and retail deposit rates.

More specifically, a bank's propensity to change its deposit rate at date $t$ is represented as a latent (unobserved) variable, $\boldsymbol{y}_{\boldsymbol{t}}$. If $\boldsymbol{y}_{\boldsymbol{t}}$ is less than some critical value, that is, $\boldsymbol{y}_{\boldsymbol{t}}<\boldsymbol{y}^{*}$, then the bank will choose to lower its deposit rate; if $\boldsymbol{y}^{*} \leq \boldsymbol{y}_{\boldsymbol{t}} \leq \boldsymbol{y}^{*}+\boldsymbol{c}$, then the bank will choose not to change its deposit rate; and lastly, if $\boldsymbol{y}^{*}+\boldsymbol{c}<\boldsymbol{y}_{\boldsymbol{t}}$, then the bank will choose to raise its deposit rate. $\boldsymbol{y}_{\boldsymbol{t}}$ is assumed to depend on the change in the market (wholesale) rate, the degree of concentration in the bank's local deposit market, the spread between the market and deposit rates, and the basispoint region (mantissa) of last period's percentage deposit rate. The following linear relationship is assumed:

$$
y_{t}=\beta_{0}+\beta_{1} \Delta r_{t}+\sum_{j=2}^{20} \beta_{j} d_{j} \cdot \Delta r_{t}+\beta_{21} \mu_{t} \cdot \Delta r_{t}+\beta_{22}\left(r_{t-1}-r_{d, t-1}\right)+\varepsilon_{t} \text {, }
$$

where $\Delta r_{t} \equiv\left(r_{t}-r_{t-1}\right)$ is the change in the wholesale market rate from date $t-1$ to date $t$, the $d_{j}$ are a set of dummy variables that indicate the basis-point region of $\boldsymbol{r}_{\boldsymbol{d}, t-1}, \boldsymbol{\mu}_{t}$ is the Herfindahl measure of bank deposit market concentration at date $t,\left(\boldsymbol{r}_{t-1}-\boldsymbol{r}_{\boldsymbol{d}, t-1}\right)$ is the spread between the market rate and the deposit rate at date $t-1$, and $\boldsymbol{\varepsilon}_{t}$ is an independent, normally distributed error term. The

\footnotetext{
${ }^{6}$ We use the one-month LIBOR in testing MMDA rates and the corresponding three-, six-, and 12-month LIBOR in testing CD3, CD6, and CD12 rates. LIBOR is for the last trading day of each month.

${ }^{7}$ Each bank's Herfindahl index is revised on an annual basis. The methodology for constructing this index is described in Berger and Hannan (1989) and Hannan and Berger (1991).
} 
inclusion of the set of dummy variables, $\boldsymbol{d}_{j}, j=2, \ldots, 20$, will indicate whether rate stickiness depends on the basis points of the previously quoted percentage deposit rate. Since the histograms of MMDA and CD rates in figures 3 to 6 indicate spikes at every five basis points, the basis-point region was divided into 20 subintervals, with the first being percentage rates having a mantissa of 0 to 4 basis points, the second being 5 to 9 basis points, up to the twentieth region being 95 to 99 basis points. The dummy variables $\boldsymbol{d}_{j}, j=2, \ldots, 20$ take on the value of 1 if the previous percentage deposit rate had a mantissa in the $j^{\text {th }}$ region, and 0 otherwise. Hence, for a given change in the wholesale market rate, $\Delta \boldsymbol{r}_{t}$, the coefficient $\boldsymbol{\beta}_{j}$ measures the flexibility (lack of stickiness) of rates having a mantissa in the $j^{\text {th }}$ region relative to rates having a mantissa in the first region ( 0 to 4 basis points). Thus, a positive value for $\boldsymbol{\beta}_{j}, j=2, \ldots, 20$ indicates that the rates in the first region (basically, the whole-integer level) are relatively stickier than rates in the $j^{\text {th }}$ region.

Since $\boldsymbol{y}_{\boldsymbol{t}}$ is unobservable, we must rely on inferences made from an observable proxy, in this case the variable $\Delta \boldsymbol{r}_{d t}$, which is defined to equal 1 if there is a positive change in the bank's quoted deposit rate, 0 if there is no change, and -1 if there is a negative change. ${ }^{8}$ Because $\Delta \boldsymbol{r}_{d t}$ is distributed in an ordered fashion, an ordered probit is the appropriate estimation technique.

Denoting $\Phi(\bullet)$ as the standard normal cumulative distribution function and writing $\boldsymbol{y}_{\boldsymbol{t}}=\boldsymbol{\beta} \boldsymbol{X}_{\boldsymbol{t}}+\boldsymbol{\varepsilon}_{t}$, the probability of a bank making a downward revision in its deposit rate is given by

$$
P\left(\Delta r_{d t}=-1\right)=\Phi\left(\beta X_{t}\right)
$$

the probability of no revision is

$$
P\left(\Delta r_{d t}=0\right)=\boldsymbol{\Phi}\left(\beta X_{t}+c\right)-\boldsymbol{\Phi}\left(\beta X_{t}\right)
$$

and the probability of a positive revision is

\footnotetext{
8 "No change" is also defined to include interest rate movements that were less than five basis points and where the percentage rate's mantissa remained within the same one-twentieth of a percentage point region. These movements were extremely rare, and using the literal definition of no change did not affect our results.
} 


$$
P\left(\Delta r_{d t}=1\right)=1-\boldsymbol{\Phi}\left(\beta X_{t}+c\right)
$$

Thus, the log-likelihood function is

$$
\ln L=\sum_{t=1}^{N} z_{d} \ln \left[\boldsymbol{\Phi}\left(\beta X_{t}\right)\right]+z_{n} \ln \left[\mathbf{\Phi}\left(c+\beta X_{t}\right)-\Phi\left(\beta X_{t}\right)\right]+z_{u} \ln \left[1-\Phi\left(c+\beta X_{t}\right)\right]
$$

where $z_{d}, z_{n}$, and $z_{u}$ equal 1 if $\Delta r_{d t}$ equals $-1,0$, and 1 , respectively.

The estimation results are reported in table 2. For each deposit type, the parameter estimates of the coefficients multiplying the market rate, $\Delta \boldsymbol{r}_{t}$, and the market/deposit-rate spread, $\left(\boldsymbol{r}_{t-1}-\boldsymbol{r}_{d, \mathrm{t}-1}\right)$, have the expected positive signs and are highly significant. Consistent with Berger and Hannan's (1991) finding that deposits rates are stickier in more concentrated markets, the coefficients of the Herfindahl index times the market rate change, $\boldsymbol{\mu}_{t} \Delta \boldsymbol{r}_{t}$, are all negative, though only statistically significant for MMDAs and CD6s. Of most interest to the hypothesis that rates should be relatively stickier at whole digits are the coefficients of the basis-point dummy variables times the market rate change, $\boldsymbol{d}_{j} \Delta \boldsymbol{r}_{t}, j=2, \ldots, 20$. With the sole exception of the CD3, the point estimates of the coefficients of these variables are all positive, and most are statistically significant (in fact, all are significant for the CD12). When lack of significance does occur, it is

often at the quarter, half, or three-quarter digit, i.e., the coefficients on variables $d_{6} \Delta r_{t}, d_{11} \Delta r_{t}$, and $\boldsymbol{d}_{\mathbf{1 6}} \Delta \boldsymbol{r}_{\boldsymbol{t}}$. Taken together, these empirical results confirm the model's prediction that deposit rates are stickiest when set at whole-digit percentage rates, but that secondary stickiness also exists when rates are set at quarter-digit levels.

\section{III.C Evidence of a Propensity for Whole-Digit Deposit Rates at Higher Market Rates}

Based on Theorem 2 and figure 2, a bank's propensity to quote retail deposit rates at a whole digit should increase as market rates rise. To test this hypothesis, we represent a bank's propensity to quote a whole-digit rate as another latent variable, $\boldsymbol{w}_{\boldsymbol{t}}$. If $\boldsymbol{w}_{\boldsymbol{t}}$ is less than some critical value, i.e., $\boldsymbol{w}_{\boldsymbol{t}}<\boldsymbol{w}^{*}$, then the bank chooses not to quote a whole-digit percentage interest rate. If 
instead $\boldsymbol{w}_{\boldsymbol{t}} \geq \boldsymbol{w}^{*}$, then the bank chooses to quote a whole-digit rate. $\boldsymbol{w}_{\boldsymbol{t}}$ is assumed to take the form

$$
w_{t}=\beta_{0}+\beta_{1} r_{t}+\beta_{2} \sigma_{r, t}+\beta_{3} \mu_{t}+\varepsilon_{t},
$$

where $\boldsymbol{r}_{\boldsymbol{t}}$ is the market rate at date $t, \boldsymbol{\sigma}_{\boldsymbol{r}, \boldsymbol{t}}$ is the standard deviation of the market rate, and $\boldsymbol{\mu}_{t}$ is a measure of market concentration. Our theoretical model would predict a positive value for $\boldsymbol{\beta}_{\mathbf{1}}$, the coefficient of the market rate, which we again proxy by LIBOR. ${ }^{9}$ Because the volatility of market rates, $\sigma_{r, t}$, tends to be positively correlated with the level of market rates, and greater volatility could have an independent influence on the tendency to quote whole-digit rates, we also include a proxy for interest rate volatility -- the annualized standard deviation of daily LIBOR during the previous month.

In equation (8), a bank's propensity to set rates at whole digits is also allowed to depend on the level of deposit market concentration, $\boldsymbol{\mu}_{t}$, which is proxied by the Herfindahl index of the bank's local deposit market. We include this variable for two reasons. First, to the extent that market power affects the form of the deposit demand function faced by a bank, our model implies that it may influence the bank's profit-maximizing interest rate. In general, however, the effect of market power on the propensity to set whole-digit rates is theoretically ambiguous, so that the expected sign of $\boldsymbol{\beta}_{\mathbf{3}}$ is unclear. A second reason for the inclusion of $\boldsymbol{\mu}_{t}$ is to consider the possibility that setting whole-digit interest rates could be a mechanism by which banks collude, implicitly or explicitly, to maintain noncompetitive deposit rates. Such a collusive agreement would be similar in spirit to the agreement by NASDAQ security dealers to trade at even eighths, as alleged by Christie and Schultz (1994) and Christie, Harris, and Schultz (1994). Maintaining whole-digit deposit rates might serve as a price-fixing mechanism that allows banks to exert

\footnotetext{
${ }^{9}$ As before, we use LIBOR with a maturity equal to that of the corresponding retail deposit.
} 
market power. Because the ability to maintain such an agreement would be more likely in a more concentrated market, this hypothesis would imply a positive coefficient for $\boldsymbol{\beta}_{\mathbf{3}}$.

Since $\boldsymbol{w}_{\boldsymbol{t}}$ is unobserved, our tests rely on an observable proxy, namely, a variable that equals 1 when the bank sets its deposit rate at a whole digit, and 0 otherwise. This implies a probit model having the log-likelihood function

$$
\ln L=\sum_{t=1}^{N}\left(1-z_{w}\right) \ln \left[\Phi\left(\beta X_{t}\right)\right]+z_{w} \ln \left[1-\Phi\left(\beta X_{t}\right)\right],
$$

where $z_{w}$ equals 1 if the percentage deposit rate is at a whole integer level, and 0 otherwise.

The estimation results are given in table 3. With the possible exception of the CD3, there is clear evidence that the propensity to set whole-digit rates increases with the level of market rates. In addition, greater market rate volatility appears to increase the likelihood that CDs will be set at whole rates. Finally, there is mixed evidence that whole-digit rates are more common in more concentrated markets. In summary, these results support the theory's prediction that wholedigit rates are more likely as market rates rise. 


\section{III.D Evidence of a Propensity for Deposit-Rate Integer Changes at Higher Market Rates}

Another implication of figure 2 is that when market rates are high, ceteris paribus, a bank's propensity to change its quoted interest rate should fall, since the optimal deposit rate is likely to be only at whole-digit breakpoints, not points interior to whole-digit levels. However, when market rates are high and a deposit rate change does occur, the deposit rate is likely to pass from one integer level to another. More precisely, conditional on a rate change occurring, a change where rates move from $x \cdot y$ percent to $(x \pm 1) . z$ percent is more likely when market rates are high. Conversely, a change where rates move from $x . y$ percent to $x . z$ percent is more likely when market rates are low. We define the former movement as an integer change and the latter as a non-integer change and consider a test of this implication of the model.

The proposition is tested in the following manner. Conditional on a deposit rate change occurring, we examine whether an integer change is systematically related to the level of the market rate $\boldsymbol{r}_{\boldsymbol{t}}$, which we again proxy by the equivalent-maturity LIBOR. Because the volatility of market rates, $\boldsymbol{\sigma}_{r, t}$, tends to rise at higher levels of $\boldsymbol{r}_{\boldsymbol{t}}$, and because this would clearly tend to increase the propensity for integer changes, we control for this effect by including the annualized standard deviation of daily LIBOR for the previous month. Finally, for the same reasons given in the previous section, the propensity for a bank to make integer changes is allowed to depend on its Herfindahl index of market concentration, $\boldsymbol{\mu}_{t}$. More specifically, we let $\boldsymbol{v}_{\boldsymbol{t}}$ be a latent variable such that if $v_{t}<v^{*}$, any change that does occur will not be an integer change. However, if $v_{t} \geq v^{*}$, then any change will be an integer change. $\boldsymbol{v}_{t}$ is assumed to take the form

$$
v_{t}=\beta_{0}+\beta_{1} r_{t}+\beta_{2} \sigma_{r, t}+\beta_{3} \mu_{t}+\varepsilon_{t} \text {. }
$$

The estimation technique is again a probit model that uses only those observations on deposit rates for which a change occurred. 
The results are reported in table 4 . Notice from the last row that integer changes constitute approximately 24 to 29 percent of all deposit rate movements. Overall, the evidence in the table provides strong support for the model's prediction. Both higher market rates and greater market rate volatility (the CD12 being an exception with regard to volatility) increase the likelihood of an integer change. There is some indication that integer changes are less likely in more concentrated markets, at least for CD6s and CD12s. This may be due to the greater deposit rate stickiness found in those markets, a phenomenon that could reduce the likelihood of integer movements.

\section{Conclusion}

This paper examines banks' optimal deposit-rate-setting behavior when some customers have limited recall. Taking seriously the experimental evidence that individuals recall odd-ending numbers less accurately than even-ending numbers, and that expressing a number as odd-ending increases the likelihood that it will be underestimated when recalled, we model deposit demand by limited-recall customers as being a function of the floor of the percentage deposit interest rate. Our analysis shows that it is optimal for banks to set their deposit rates either at a whole integer or at an interior point that satisfies a specific first-order condition.

The model predicts that the likelihood of interest rates being set at a whole digit increases with both the proportion of limited-recall consumers in the market and advances in the wholesale market interest rate. Also, for a given market rate shock, the quoted deposit rate tends to be stickier when it is currently at a whole digit than when it is not. Lastly, although deposit rates tend to be stickier when market interest rates are high, if and when there is a change in the deposit rate, the change tends to be larger, jumping from one whole digit to another. Our tests using monthly 
MMDA and CD interest rates for over 500 individual banks during a 10-1/2-year period provide strong corroborative evidence in support of the model's implications.

Our finding that limited recall results in price stickiness has a potentially much broader significance. Price stickiness is an important theme in macroeconomics. The literature on "menu costs" posits that the presence of small direct costs of adjusting prices can result in price stickiness that has a large real impact on the economy. However, evidence for the presence of menu costs is derived mainly from evidence that prices remain unchanged. In contrast to the menu cost literature, our theory assumes no cost of adjusting prices, per se, but nevertheless results in a considerable degree of price stickiness. In addition, our theory implies that deposit rates (prices) should be stickier when they start from (just below) a whole digit. This difference in stickiness, which distinguishes our model from the menu cost approach, is in fact confirmed by our empirical tests. A promising area for future research would be to examine the macroeconomic consequences of price and interest rate stickiness generated by limited recall. 


\section{References}

Ball, C., W. Torous, and A. Tschoegl (1985) "The Degree of Price Resolution: The Case of the Gold Market," Journal of Futures Markets 5, 29-43.

Berger, A. and T. Hannan (1989) “The Price-Concentration Relationship in Banking," Review of Economics and Statistics 71, 291-299.

Blinder, A. (1991) "Why Are Prices Sticky? Preliminary Results from an Interview Study," American Economic Review: Papers and Proceedings 81, 89-96.

Brenner, G. and R. Brenner (1982) "Memory and Markets, or Why Are You Paying \$2.99 for a Widget?" Journal of Business 55, 147-158.

Brown, S., P. Laux, and B. Schachter (1991) "On the Existence of an Optimal Tick Size," Review of Futures Markets 10, 50-72.

Christie, W. and P. Schultz (1994) "Why Do NASDAQ Market Makers Avoid Odd-Eighths Quotes?” Journal of Finance 49, 1813-1840.

Christie, W., J. Harris, and P. Schultz (1994) "Why Did NASDAQ Market Makers Stop Avoiding Odd-Eighths Quotes?” Journal of Finance 49, 1841-1860.

Colwell, P., P. Rushing, and K. Young (1994) “The Rounding of Appraisal Estimates," Illinois Real Estate Letter, Summer/Fall.

Davis, R., L. Korobow, and J. Wenninger (1987) "Bankers on Pricing Consumer Deposits," Federal Reserve Bank of New York, Quarterly Review, Winter, 6-13.

Diebold, F. and S. Sharpe (1990) "Post-Deregulation Bank-Deposit-Rate Pricing: The Multivariate Dynamics,” Journal of Business and Economic Statistics 8, 281-291.

Friedman, L. (1967) "Psychological Pricing in the Food Industry," in A. Phillips and O. Williamson, eds., Prices: Issues in Theory, Practice, and Public Policy, University of Pennsylvania Press, Philadelphia, 187-201.

Goodhart, C. and R. Curcio (1990) "Asset Price Discovery and Price Clustering in the Foreign Exchange Market,” London School of Economics, Working Paper.

Hannan, T. and A. Berger (1991) "The Rigidity of Prices: Evidence from the Banking Industry," American Economic Review 81, 938-945.

Harris, L. (1991) “Stock Price Clustering and Discreteness," Review of Financial Studies 4, 389-415. 
Hutchison, D. and G. Pennacchi (1996) "Measuring Rents and Interest Rate Risk in Imperfect Financial Markets: The Case of Retail Bank Deposits," Journal of Financial and Quantitative Analysis (forthcoming).

Kashyap, A. (1995) "Sticky Prices: New Evidence from Retail Catalogs," Quarterly Journal of Economics 110, 245-274.

Neumark, D. and S. Sharpe (1992) "Market Structure and the Nature of Price Rigidity: Evidence from the Market for Consumer Deposits," Quarterly Journal of Economics 107, 657-680.

Nierderhoffer, V. (1965) “Clustering of Stock Prices," Operations Research 13, 258-265.

Osborne, M.F.M. (1962) "Periodic Structure in the Brownian Motion of Stock Prices," Operations Research 10, 345-379.

Rosen, R. (1995) "What Goes Up Must Come Down? Asymmetries and Persistence in Bank Deposit Rates,” Finance Department, Indiana University, mimeo.

Schindler, R. and A. Wiman (1989) "Effects of Odd Pricing on Price Recall," Journal of Business Research 19, 165-177.

Wisniewski, K. and R. Blattberg (1983) "Response Function Estimation Using UPC Scanner Data: An Analytical Approach to Demand Estimation under Dealing," in F. Zufryden, ed., Advances and Practice of Marketing Science, Institute of Management Science, Providence, R.I., 300-311. 


\section{Table 1}

\section{Basis-Point Distribution of Deposit Interest Rates}

\begin{tabular}{lcccccc}
\hline \multicolumn{5}{c}{ Percentage of Observations within Quartile } & & \\
Deposit & Quartile 1 & Quartile 2 & Quartile 3 & Quartile 4 & No. of Obs. & $\chi^{2}(3)$ \\
MMDA & 29.4 & 26.3 & 25.3 & 19.0 & 42,202 & 964.3 \\
CD3 & 27.5 & 24.0 & 25.5 & 23.0 & 49,137 & 224.6 \\
CD6 & 26.4 & 25.1 & 26.2 & 22.2 & 50,340 & 222.4 \\
CD12 & 28.4 & 22.8 & 26.1 & 22.7 & 49,909 & 453.8 \\
\hline
\end{tabular}

Note: The basis points included in the above quartiles are as follows: 0 to 24 basis points for quartile $1 ; 25$ to 49 basis points for quartile $2 ; 50$ to 74 basis points for quartile 3 ; and 75 to 99 basis points for quartile 4 . The $\chi^{2}$ statistic tests the null hypothesis that the distribution of observations across quartiles is uniform. Since $\left.\chi^{2}(3)\right|_{1 \%}=7.8$, the null is rejected in each case.

Source: Authors'calculations. 
Table 2

Estimates of the Propensity to Change Deposit Rates

$$
y_{t}=\beta_{0}+\beta_{1} \Delta r_{t}+\sum_{j=2}^{20} \beta_{j} d_{j} \cdot \Delta r_{t}+\beta_{21} \mu_{t} \cdot \Delta r_{t}+\beta_{22}\left(r_{t-1}-r_{d, t-1}\right)+\varepsilon_{t}
$$

\begin{tabular}{|c|c|c|c|c|}
\hline \multirow[b]{2}{*}{ Coefficient of } & \multicolumn{4}{|c|}{$\begin{array}{l}\text { Parameter Estimates of Deposit-Rate-Change Model } \\
\text { (Standard Errors Are in Parentheses) }\end{array}$} \\
\hline & MMDA & CD3 & CD6 & CD12 \\
\hline$\Delta \mathrm{r}_{\mathrm{t}}$ & $\begin{array}{r}103.85^{*} \\
(3.89)\end{array}$ & $\begin{array}{r}119.97 * \\
(3.96)\end{array}$ & $\begin{array}{r}130.50 * \\
(3.49)\end{array}$ & $\begin{array}{r}101.33^{*} \\
(3.08)\end{array}$ \\
\hline $\mathrm{d}_{2} \Delta \mathrm{r}_{\mathrm{t}}: 5-9 \mathrm{bp}$ & $\begin{array}{c}24.42 * \\
(8.38)\end{array}$ & $\begin{array}{r}46.27^{*} \\
(9.42)\end{array}$ & $\begin{array}{l}43.12^{*} \\
(8.21)\end{array}$ & $\begin{array}{l}40.70^{*} \\
(7.93)\end{array}$ \\
\hline $\mathrm{d}_{3} \Delta \mathrm{r}_{\mathrm{t}}: 10-14 \mathrm{bp}$ & $\begin{array}{c}3.99 \\
(6.92)\end{array}$ & $\begin{array}{r}20.69^{*} \\
(6.77)\end{array}$ & $\begin{array}{l}21.62^{*} \\
(6.06)\end{array}$ & $\begin{array}{r}40.23^{*} \\
(5.53)\end{array}$ \\
\hline $\mathrm{d}_{4} \Delta \mathrm{r}_{\mathrm{t}}: 15-19 \mathrm{bp}$ & $\begin{array}{l}27.24 * \\
(7.70)\end{array}$ & $\begin{array}{l}40.83^{*} \\
(8.10)\end{array}$ & $\begin{array}{l}42.04 * \\
(7.29)\end{array}$ & $\begin{array}{l}52.24^{*} \\
(6.61)\end{array}$ \\
\hline $\mathrm{d}_{5} \Delta \mathrm{r}_{\mathrm{t}}: 20-24 \mathrm{bp}$ & $\begin{array}{l}18.95^{*} \\
(8.40)\end{array}$ & $\begin{array}{l}38.71^{*} \\
(7.46)\end{array}$ & $\begin{array}{l}27.30^{*} \\
(7.17)\end{array}$ & $\begin{array}{l}54.42 * \\
(6.65)\end{array}$ \\
\hline $\mathrm{d}_{6} \Delta \mathrm{r}_{\mathrm{t}}: 25-29 \mathrm{bp}$ & $\begin{array}{l}1.65 \\
(5.12)\end{array}$ & $\begin{array}{c}0.39 \\
(5.34)\end{array}$ & $\begin{array}{c}8.89 \\
(4.85)\end{array}$ & $\begin{array}{r}21.11^{*} \\
(4.39)\end{array}$ \\
\hline $\mathrm{d}_{7} \Delta \mathrm{r}_{\mathrm{t}}: 30-34 \mathrm{bp}$ & $\begin{array}{l}22.04 * \\
(7.73)\end{array}$ & $\begin{array}{l}20.50^{*} \\
(7.89)\end{array}$ & $\begin{array}{l}22.39^{*} \\
(6.93)\end{array}$ & $\begin{array}{l}48.05^{*} \\
(6.48)\end{array}$ \\
\hline $\mathrm{d}_{8} \Delta \mathrm{r}_{\mathrm{t}}: 35-39 \mathrm{bp}$ & $\begin{array}{l}24.31^{*} \\
(6.89)\end{array}$ & $\begin{array}{l}24.13^{*} \\
(6.97)\end{array}$ & $\begin{array}{l}11.08 \\
(6.02)\end{array}$ & $\begin{array}{l}45.67^{*} \\
(6.06)\end{array}$ \\
\hline $\mathrm{d}_{9} \Delta \mathrm{r}_{\mathrm{t}}: 40-44 \mathrm{bp}$ & $\begin{array}{l}23.10^{*} \\
(6.65)\end{array}$ & $\begin{array}{l}46.58^{*} \\
(7.53)\end{array}$ & $\begin{array}{l}29.46^{*} \\
(6.18)\end{array}$ & $\begin{array}{l}46.80^{*} \\
(6.11)\end{array}$ \\
\hline $\mathrm{d}_{10} \Delta \mathrm{r}_{\mathrm{t}}: 45-49 \mathrm{bp}$ & $\begin{array}{c}8.74 \\
(7.98)\end{array}$ & $\begin{array}{l}43.08^{*} \\
(9.80)\end{array}$ & $\begin{array}{l}45.44^{*} \\
(8.64)\end{array}$ & $\begin{array}{l}19.50^{*} \\
(6.96)\end{array}$ \\
\hline $\mathrm{d}_{11} \Delta \mathrm{r}_{\mathrm{t}}: 50-54 \mathrm{bp}$ & $\begin{array}{c}2.19 \\
(4.97)\end{array}$ & $\begin{array}{l}-2.74 \\
(5.01)\end{array}$ & $\begin{array}{l}13.64^{*} \\
(4.67)\end{array}$ & $\begin{array}{l}18.02^{*} \\
(4.14)\end{array}$ \\
\hline $\mathrm{d}_{12} \Delta \mathrm{r}_{\mathrm{t}}: 55-59 \mathrm{bp}$ & $\begin{array}{c}5.16 \\
(8.58)\end{array}$ & $\begin{array}{l}11.53 \\
(8.28)\end{array}$ & $\begin{array}{l}26.80^{*} \\
(7.63)\end{array}$ & $\begin{array}{l}47.07^{*} \\
(7.29)\end{array}$ \\
\hline $\mathrm{d}_{13} \Delta \mathrm{r}_{\mathrm{t}}: 60-64 \mathrm{bp}$ & $\begin{array}{l}41.14^{*} \\
(6.53)\end{array}$ & $\begin{array}{l}22.48^{*} \\
(6.64)\end{array}$ & $\begin{array}{l}17.95^{*} \\
(5.50)\end{array}$ & $\begin{array}{r}26.86^{*} \\
(5.30)\end{array}$ \\
\hline $\mathrm{d}_{14} \Delta \mathrm{r}_{\mathrm{t}}: 65-69 \mathrm{bp}$ & $\begin{array}{l}37.04^{*} \\
(7.80)\end{array}$ & $\begin{array}{l}38.95^{*} \\
(8.49)\end{array}$ & $\begin{array}{l}12.90 \\
(7.13)\end{array}$ & $\begin{array}{l}23.44^{*} \\
(6.46)\end{array}$ \\
\hline $\mathrm{d}_{15} \Delta \mathrm{r}_{\mathrm{t}}: 70-74 \mathrm{bp}$ & $\begin{array}{l}73.77^{*} \\
(7.91)\end{array}$ & $\begin{array}{l}15.69 \\
(7.75)\end{array}$ & $\begin{array}{l}33.02 * \\
(7.11)\end{array}$ & $\begin{array}{l}37.91^{*} \\
(5.92)\end{array}$ \\
\hline $\mathrm{d}_{16} \Delta \mathrm{r}_{\mathrm{t}}: 75-79 \mathrm{bp}$ & $\begin{array}{l}32.54^{*} \\
(5.44)\end{array}$ & $\begin{array}{r}-15.38^{*} \\
(5.08)\end{array}$ & $\begin{array}{c}6.12 \\
(4.73)\end{array}$ & $\begin{array}{l}15.06^{*} \\
(4.24)\end{array}$ \\
\hline $\mathrm{d}_{17} \Delta \mathrm{r}_{\mathrm{t}}: 80-84 \mathrm{bp}$ & $\begin{array}{l}26.60^{*} \\
(7.77)\end{array}$ & $\begin{array}{l}-5.94 \\
(7.18)\end{array}$ & $\begin{array}{l}38.96^{*} \\
(6.81)\end{array}$ & $\begin{array}{l}51.54^{*} \\
(6.35)\end{array}$ \\
\hline $\mathrm{d}_{18} \Delta \mathrm{r}_{\mathrm{t}}: 85-89 \mathrm{bp}$ & $\begin{array}{l}63.20^{*} \\
(7.91)\end{array}$ & $\begin{array}{l}46.67^{*} \\
(7.82)\end{array}$ & $\begin{array}{l}14.12^{*} \\
(6.04)\end{array}$ & $\begin{array}{l}40.85^{*} \\
(5.90)\end{array}$ \\
\hline $\mathrm{d}_{19} \Delta \mathrm{r}_{\mathrm{t}}: 90-94 \mathrm{bp}$ & $\begin{array}{l}51.96^{*} \\
(8.36)\end{array}$ & $\begin{array}{l}43.15^{*} \\
(7.95)\end{array}$ & $\begin{array}{l}28.11^{*} \\
(7.10)\end{array}$ & $\begin{array}{l}32.88^{*} \\
(6.27)\end{array}$ \\
\hline $\mathrm{d}_{20} \Delta \mathrm{r}_{\mathrm{t}}: 95-99 \mathrm{bp}$ & $\begin{array}{c}4.47 \\
(10.62)\end{array}$ & $\begin{array}{l}34.20^{*} \\
(9.75)\end{array}$ & $\begin{array}{l}16.26 \\
(9.13)\end{array}$ & $\begin{array}{c}43.24^{*} \\
(8.11)\end{array}$ \\
\hline$\mu_{\mathrm{t}} \Delta \mathrm{r}_{\mathrm{t}}:$ Herfindahl & $\begin{array}{l}-63.31 * \\
(10.21)\end{array}$ & $\begin{array}{c}-2.68 \\
(10.43)\end{array}$ & $\begin{array}{c}-27.53^{*} \\
(9.37)\end{array}$ & $\begin{array}{r}-16.61 \\
(8.71)\end{array}$ \\
\hline$r_{t-1}-r_{d, t-1}$ & $\begin{array}{l}30.05^{*} \\
(0.62)\end{array}$ & $\begin{array}{c}29.84^{*} \\
(0.60)\end{array}$ & $\begin{array}{c}51.48^{*} \\
(0.76)\end{array}$ & $\begin{array}{c}34.45^{*} \\
(0.52)\end{array}$ \\
\hline Total Observations & 42,202 & 49,137 & 50,340 & 49,909 \\
\hline
\end{tabular}

Note: Asterisk indicates significance at the 5 percent confidence level.

Source: Authors' calculations. 
Table 3

\section{Estimates of Propensity to Set Whole-Digit Deposit Rates}

\begin{tabular}{|c|c|c|c|c|}
\hline \multirow[b]{2}{*}{ Coefficient of } & \multicolumn{3}{|c|}{$\begin{array}{l}\text { Parameter Estimates of Whole-Digit Deposit Rate Model } \\
\text { (Standard Errors Are in Parentheses) }\end{array}$} & \multirow[b]{2}{*}{ CD12 } \\
\hline & MMDA & CD3 & CD6 & \\
\hline$r_{t}$ & $\begin{array}{r}0.0478^{*} \\
(0.0044)\end{array}$ & $\begin{array}{c}0.0042 \\
(0.0038)\end{array}$ & $\begin{array}{c}0.0113^{*} \\
(0.0038)\end{array}$ & $\begin{array}{r}0.0368^{*} \\
(0.0034)\end{array}$ \\
\hline$\sigma_{\mathrm{r}, \mathrm{t}}$ & $\begin{array}{l}-0.1245 \\
(0.0652)\end{array}$ & $\begin{array}{r}0.2362 * \\
(0.0790)\end{array}$ & $\begin{array}{c}0.6003^{*} \\
(0.0796)\end{array}$ & $\begin{array}{r}0.0388^{*} \\
(0.0144)\end{array}$ \\
\hline$\mu_{\mathrm{t}}:$ Herfindahl & $\begin{array}{c}0.0704 \\
(0.0602)\end{array}$ & $\begin{array}{c}0.1118 \\
(0.0585)\end{array}$ & $\begin{array}{l}-0.0448 \\
(0.0614)\end{array}$ & $\begin{array}{r}0.3646^{*} \\
(0.0552)\end{array}$ \\
\hline Total Observations & 42,202 & 49,137 & 50,340 & 49,909 \\
\hline$\%$ Obs. at Whole Digit & 15.84 & 13.44 & 11.60 & 14.16 \\
\hline
\end{tabular}

Table 4

Estimates of Propensity for Integer Changes in Deposit Rates

$$
v_{t}=\beta_{0}+\beta_{1} r_{t}+\beta_{2} \sigma_{r, t}+\beta_{3} \mu_{t}+\varepsilon_{t}
$$

\begin{tabular}{ccccc}
\hline & \multicolumn{3}{c}{ Parameter Estimates of Model with Integer-Deposit-Rate Changes } \\
Coefficient of & MMDA & CD3 & CD6 & CD12 \\
$\mathrm{r}_{\mathrm{t}}$ & $0.0465^{*}$ & $0.0509^{*}$ & $0.0276^{*}$ & $0.0824^{*}$ \\
& $(0.0056)$ & $(0.0044)$ & $(0.0040)$ & $(0.0041)$ \\
$\sigma_{\mathrm{r}, \mathrm{t}}$ & $1.2715^{*}$ & $1.5613^{*}$ & $1.7548^{*}$ & $-0.0553^{*}$ \\
& $(0.0803)$ & $(0.0813)$ & $(0.0766)$ & $(0.0182)$ \\
$\mu_{\mathrm{t}}:$ Herfindahl & -0.0308 & -0.0372 & $-0.1519^{*}$ & $-0.5986^{*}$ \\
& $(0.0832)$ & $(0.0641)$ & $(0.0610)$ & $(0.0779)$ \\
Total Rate Changes & 19,651 & 28,780 & 34,540 & 33,881 \\
& & & & 28.60
\end{tabular}

Note: Asterisk indicates significance at the 5 percent confidence level.

Source: Authors' calculations. 


\section{Figure 1}

\section{Bank Profits and Deposit Rate}

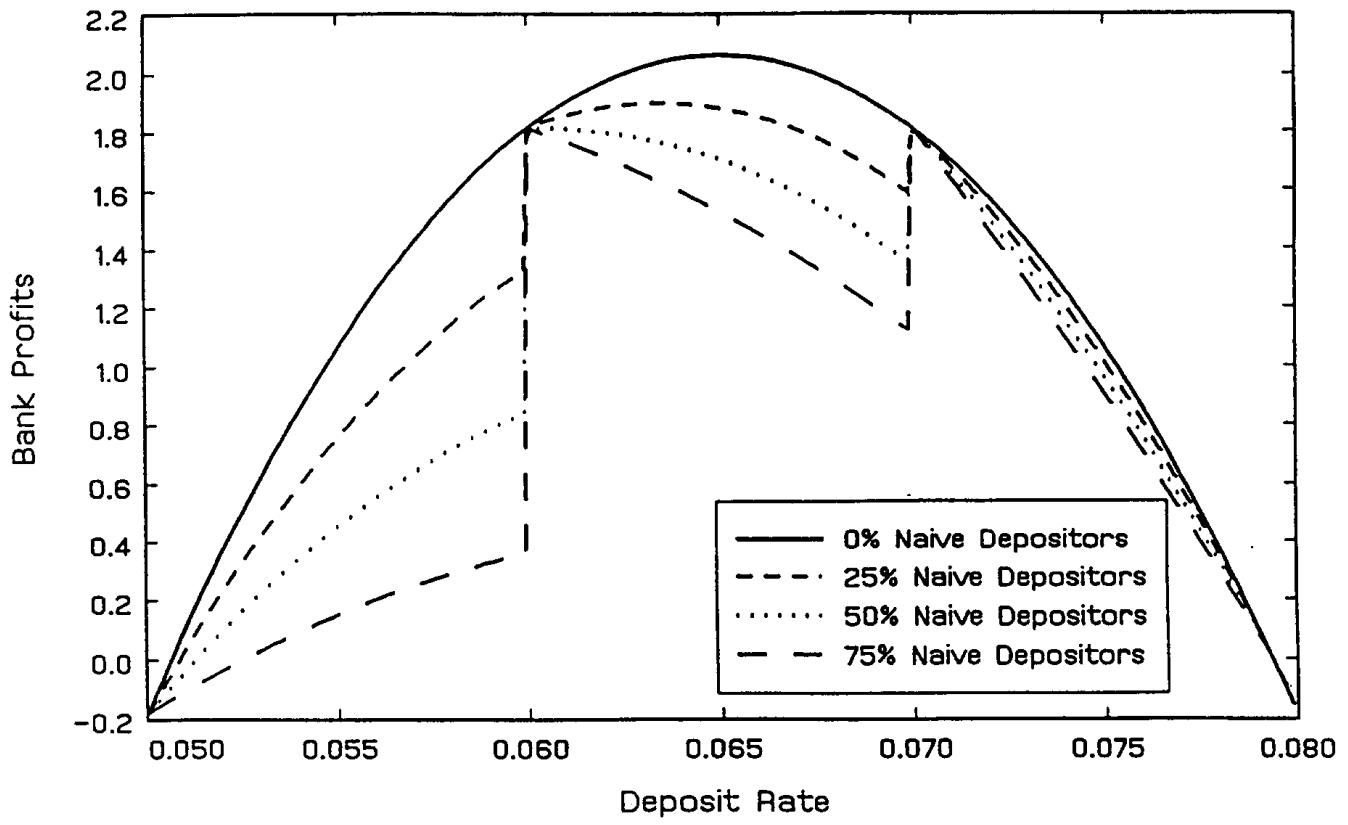

Source: Authors' calculations. 
Figure 2

Optimal Bank Deposit Rate 50\% Naive Depositors

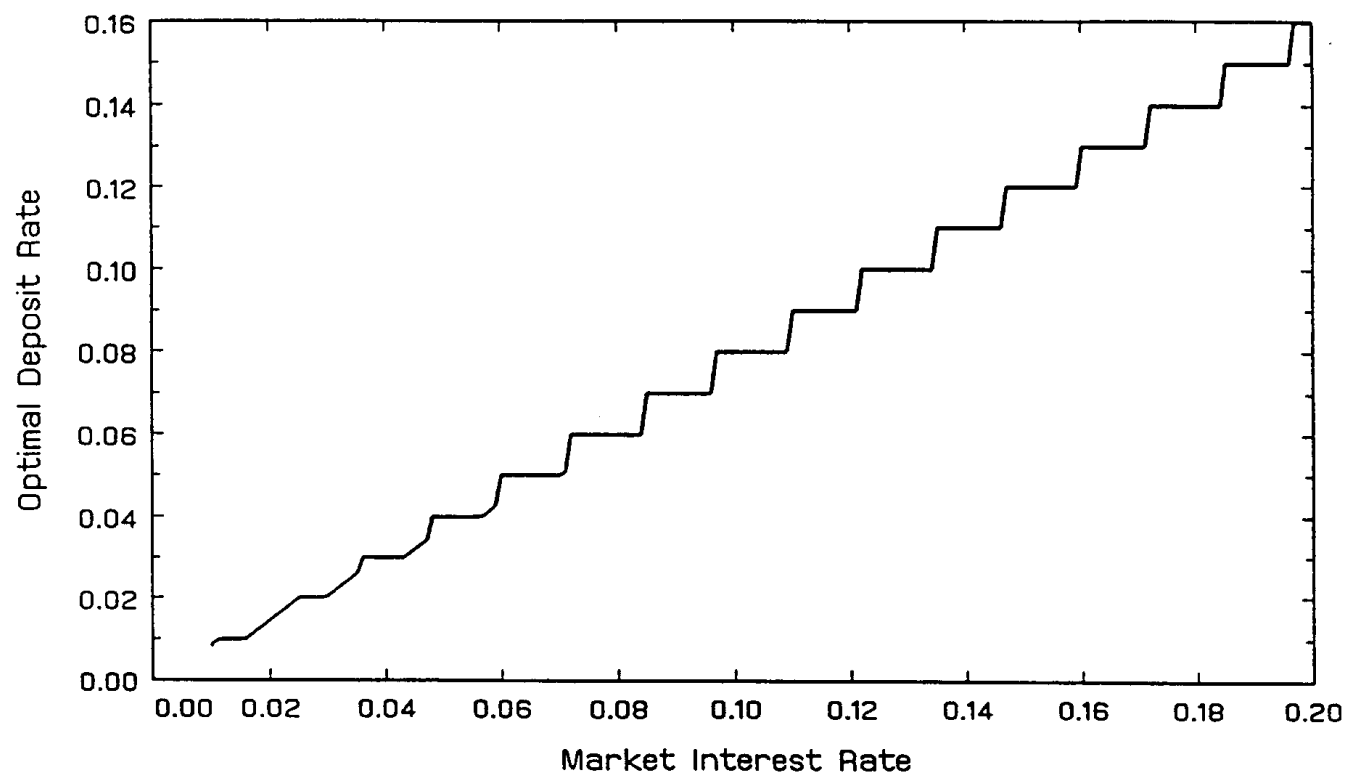

Source: Authors' calculations. 
Figure 3

MMDA Rate Distribution

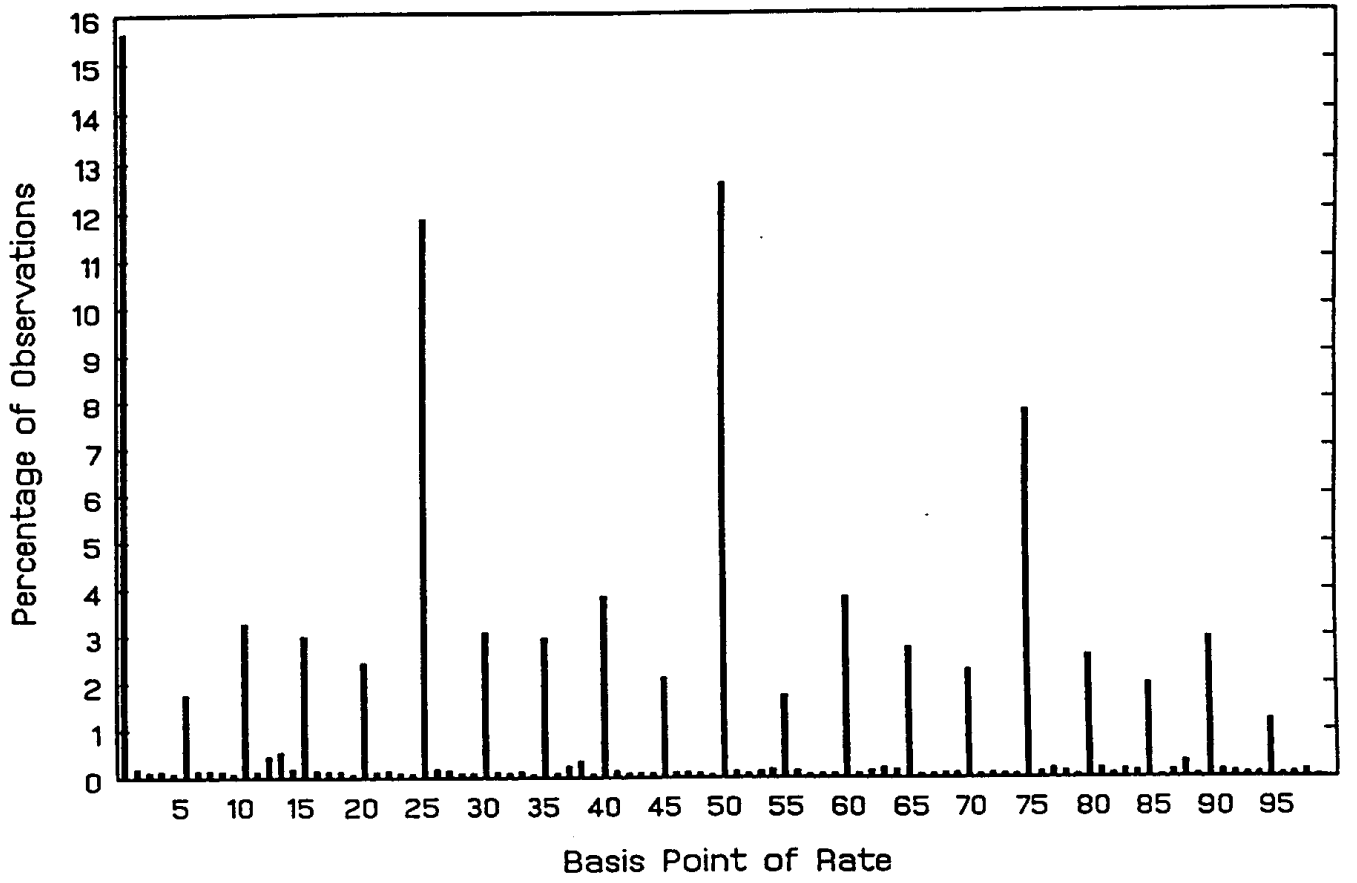

Source: Authors' calculations. 
Figure 4

Three-Month CD Rate Distribution

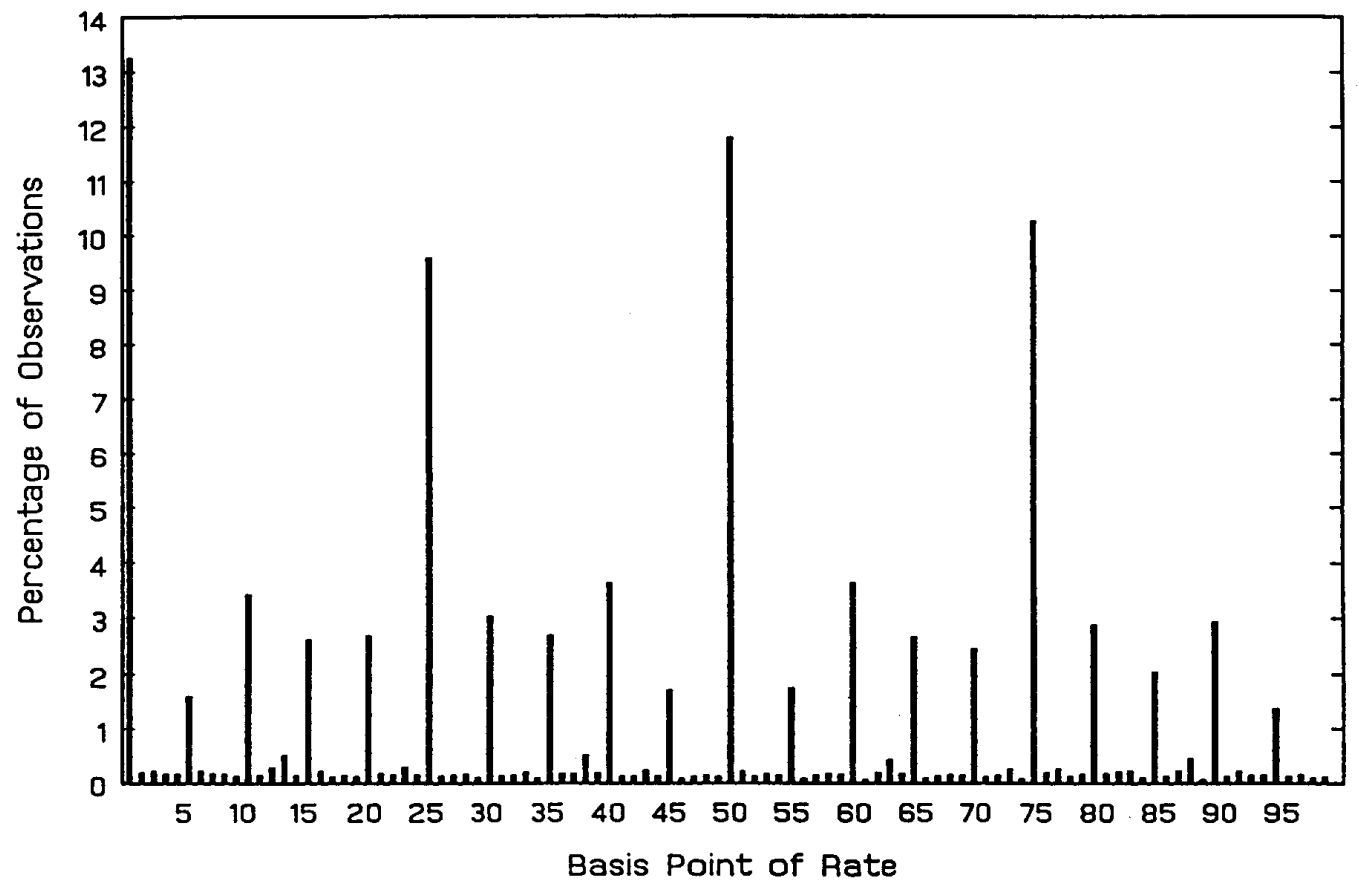

Source: Authors' calculations. 
Figure 5

Six-Month CD Rate Distribution

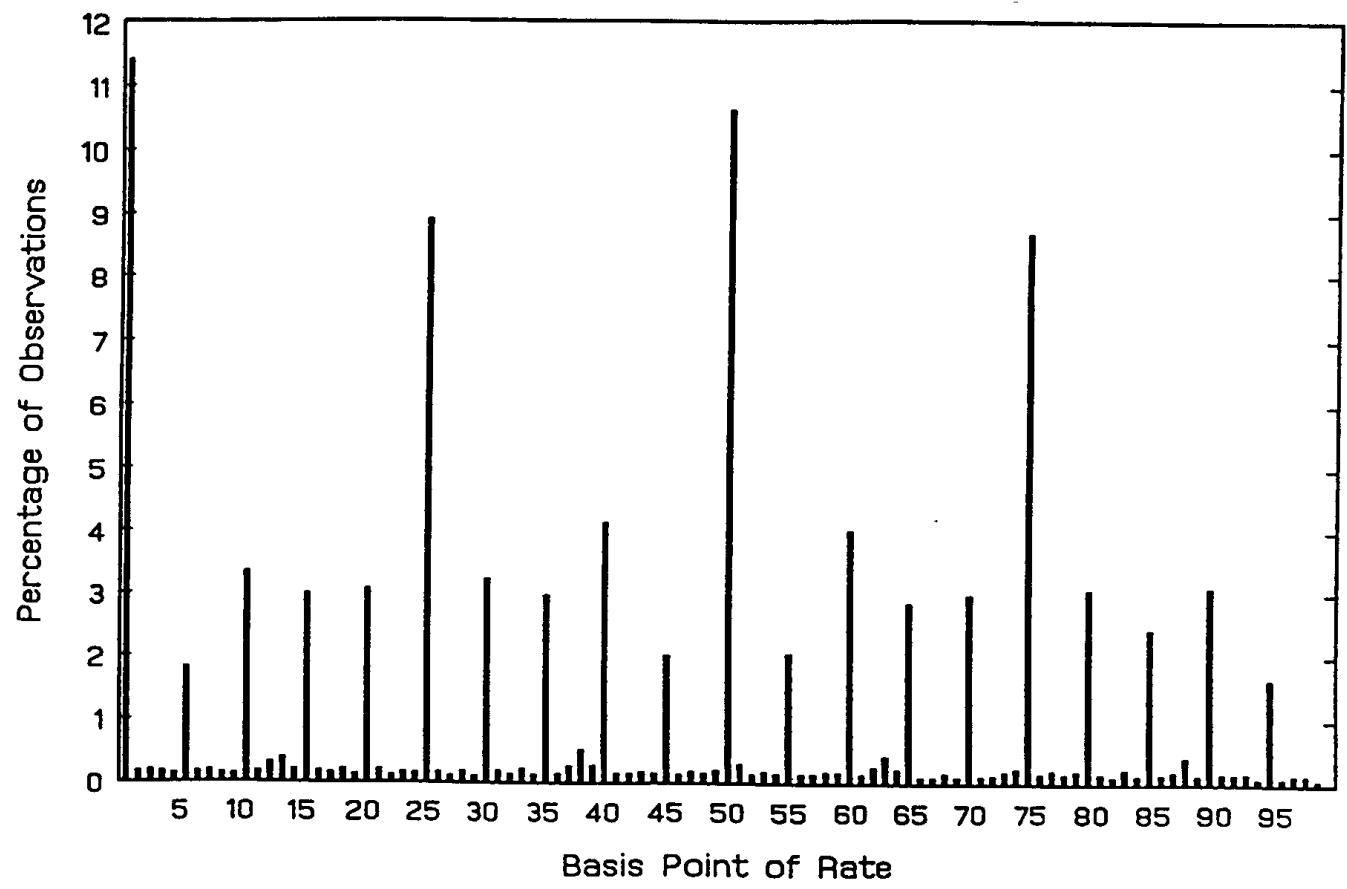

Source: Authors' calculations. 
Figure 6

Twelve-Month CD Rate Distribution

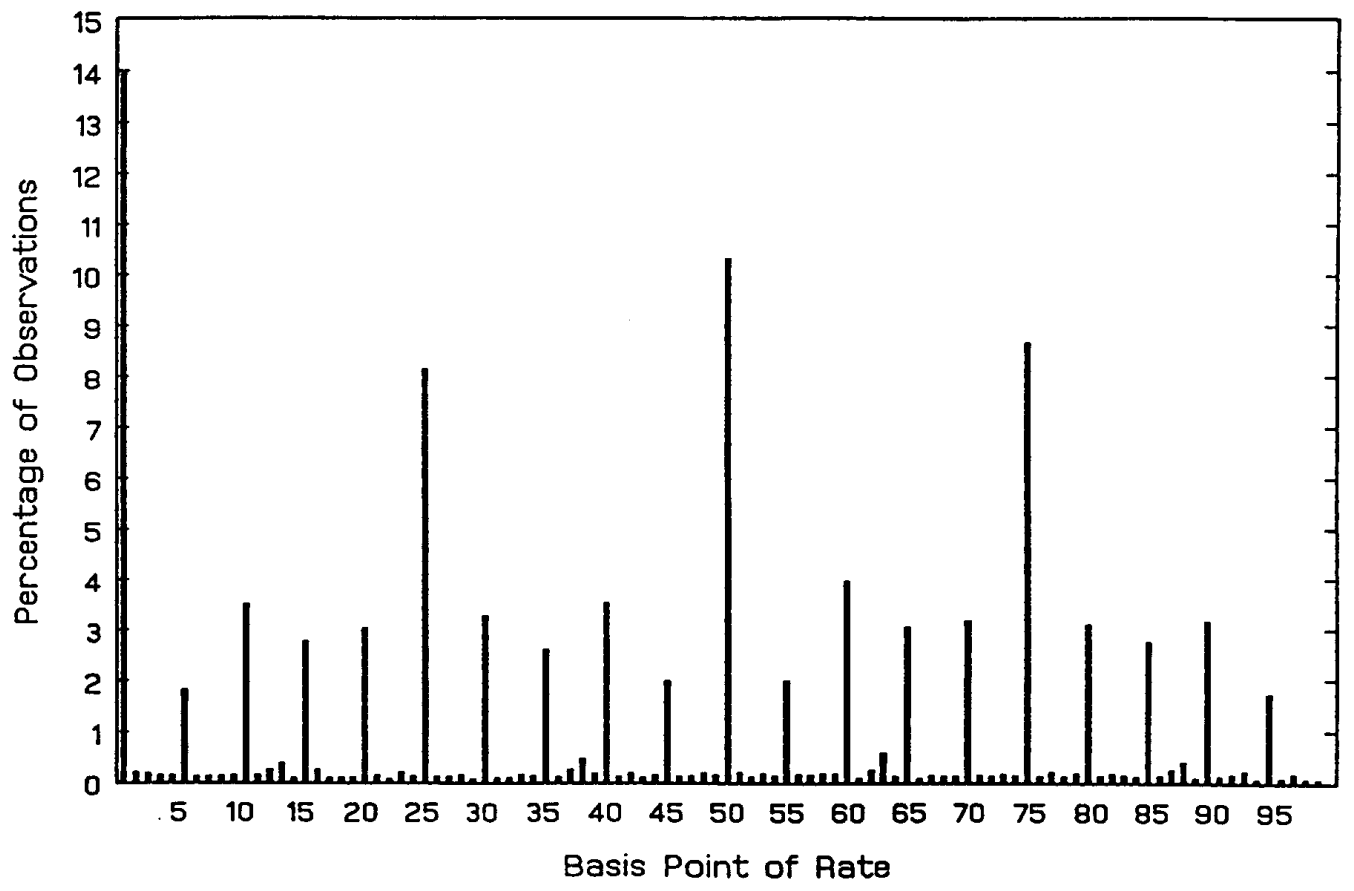

Source: Authors' calculations. 